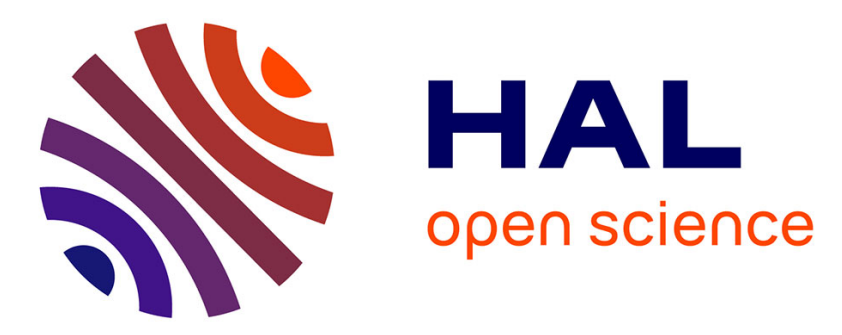

\title{
Evaluation of three different microbial inhibition tests for the detection of sulphamethazine residues in the edible tissues of rabbits
}

\author{
Ivona Kožárová, Jana Janošová, Dioniz Máté, Soòa Tkáčiková
}

\section{To cite this version:}

Ivona Kožárová, Jana Janošová, Dioniz Máté, Soòa Tkáčiková. Evaluation of three different microbial inhibition tests for the detection of sulphamethazine residues in the edible tissues of rabbits. Food Additives and Contaminants, 2009, 26 (07), pp.978-987. 10.1080/02652030902839715 . hal-00573871

\section{HAL Id: hal-00573871 \\ https://hal.science/hal-00573871}

Submitted on 5 Mar 2011

HAL is a multi-disciplinary open access archive for the deposit and dissemination of scientific research documents, whether they are published or not. The documents may come from teaching and research institutions in France or abroad, or from public or private research centers.
L'archive ouverte pluridisciplinaire HAL, est destinée au dépôt et à la diffusion de documents scientifiques de niveau recherche, publiés ou non, émanant des établissements d'enseignement et de recherche français ou étrangers, des laboratoires publics ou privés. 


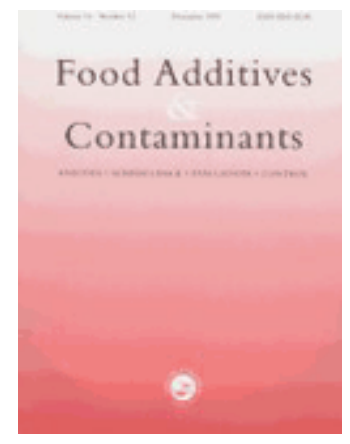

\section{Evaluation of three different microbial inhibition tests for the detection of sulphamethazine residues in the edible tissues of rabbits}

\begin{tabular}{|c|c|}
\hline Journal: & Food Additives and Contaminants \\
\hline Manuscript ID: & TFAC-2008-305.R1 \\
\hline Manuscript Type: & Original Research Paper \\
\hline $\begin{array}{r}\text { Date Submitted by the } \\
\text { Author: }\end{array}$ & 18-Feb-2009 \\
\hline Complete List of Authors: & $\begin{array}{l}\text { Kožárová, Ivona; University of Veterinary Medicine in KoÂ } 1 \text { ice, } \\
\text { Food Hygiene and Technology } \\
\text { Janošová, Jana; University of Veterinary Medicine in KoẪ ice, } \\
\text { Department of Chemistry, Biochemistry and Biophysics } \\
\text { Máté, Dionı; University of Veterinary Medicine in KoẪ ice, Food } \\
\text { Hygiene and Technology } \\
\text { Tkáčiková, Soòa; State Veterinary Institute KoÂl ice }\end{array}$ \\
\hline Methods/Techniques: & $\begin{array}{l}\text { Chromatography - HPLC, Screening - microbial screening, } \\
\text { Screening assays }\end{array}$ \\
\hline Additives/Contaminants: & Veterinary drug residues - sulphonamides \\
\hline Food Types: & Animal products - meat \\
\hline
\end{tabular}

\section{SCHOLARONE ${ }^{m}$ \\ Manuscripts}




\section{Abstract}

The aim of the present study was to evaluate three microbial inhibition tests (MIT) based on the inhibition of the growth of the test organism, (a) the Four Plate Test (FPT) containing Bacillus subtilis BGA; (b) the Screening Test for Antibiotic Residues (STAR) containing Bacillus stearothermophilus var. calidolactis ATCC 10149, and (c) the Premi ${ }^{\circledR}$ Test containing Bacillus stearothermophilus var. calidolactis. The tests were used for determining sulphamethazine (SMZ) residues in edible tissues of rabbits after its oral administration up to day 15 of the withdrawal period (WP). A solvent extraction procedure was used to enhance the capability of the tests to detect SMZ residues at or below maximum residue limit (MRL), and para-aminobenzoic acid (PABA) was employed to identify SMZ residues already in the first stage of the residue screening. The presence of SMZ residues in the samples was confirmed and quantified by a validated HPLC method. The Premi ${ }^{\circledR}$ Test detected SMZ residues in the muscle and heart tissue up to day 9 of the WP and in the liver, lungs and kidneys up to day 10 of the WP. The STAR detected SMZ residues in the edible organs of rabbits up to day 8 of the WP. The kidneys were positive up to day 5 of the WP, the liver until day 4 of the WP and the lungs until day 3 of the WP. No SMZ residues were detected in the muscle and heart. By using the solvent extraction procedure, SMZ residues were detected in the muscle extract up to day 10 of the WP and the muscle was positive until day 6 of the WP. No detection sensitivity was observed by using the FPT. After the solvent extraction, SMZ residues were detected in the muscle extract until day 8 of the WP and the muscle was positive until day 3 of the WP. No positive results were detected after the addition of PABA into/onto the agar medium. PABA at the concentration of $10 \mu \mathrm{g} \cdot \mathrm{ml}^{-1}$ completely reversed the inhibitory activity of SMZ and enabled reliable identification of SMZ in the examined samples. By using the HPLC, SMZ was detected in the muscle samples until day 10 of WP $\left(0.02 \mathrm{mg} \cdot \mathrm{kg}^{-1}\right)$ and in the liver until day 12 of the WP $\left(0.09 \mathrm{mg} \cdot \mathrm{kg}^{-1}\right)$. The results obtained by the HPLC method and the limit of detection (LOD) of screening tests for SMZ (FPT 0.4 $\mu \mathrm{g} \cdot \mathrm{ml}^{-1}$, STAR $0.2 \mu \mathrm{g} \cdot \mathrm{ml}^{-1}$, Premi ${ }^{\circledR}$ Test $0.05 \mu \mathrm{g} \cdot \mathrm{ml}^{-1}$ ) allowed us to state that the most suitable screening tests for the detection of SMZ residues in the edible tissues of rabbits at the level corresponding to MRL of $0.1 \mathrm{mg} \cdot \mathrm{kg}^{-1}$, established for sulphonamides, are the Premi ${ }^{\circledR}$ Test and the STAR in conjunction with the solvent-extraction procedure.

Keywords: sulphamethazine, residues, detection, rabbit tissues, microbial inhibition tests, $H P L C$ 


\section{Introduction}

Sulphonamides are one of the oldest groups of pharmacologically active substances used in veterinary medicine to date. Their discovery in 1935 signified the beginning of a new era in the treatment of a wide range of bacterial diseases and a number of protozoan infections. In rabbits, sulphonamides have been used for the treatment of coccidiosis. Because of concerns related to sulphonamide residues in food products of animal origin, they must be administered only in recommended concentrations and their respective withdrawal times must be observed..

Council Regulation (EEC) No. $2377 / 90$ establishes the MRL of $0.1 \mathrm{mg} \cdot \mathrm{kg}^{-1}$ for sulphonamides (all compounds of the sulphonamide group) in foods of animal origin. The MRL is defined as the maximum concentration of residue resulting from the use of veterinary medicinal products (expressed in mg. $\mathrm{kg}^{-1}$ or $\mu \mathrm{g} \cdot \mathrm{kg}^{-1}$ on a fresh weight basis), which is legally permitted by the Community as acceptable in or on food (EC 1990). There is a requirement set by the Council Directive 96/23/EC to screen live animals and animal products for residues of antimicrobial drugs (EC 1996).

MIT are widely used in the screening of antimicrobial residues in food-producing animals and their animal products. MIT are based on inhibiting of the growth of test organisms sensitive to many antibiotics and sulphonamides. Among these tests, the FPT (Bogaerts and Wolf 1980), the STAR developed at the Community Reference Laboratory in Fougères (France) and the Premi ${ }^{\circledR}$ Test developed by DSM Gist B.V. (The Netherlands) have been most widely used in the residue screening.

The FPT and STAR are plate agar diffusion tests in which the presence of an antibacterial substance is expressed by the production of an inhibition zone. The FPT consists of plates with Bacillus subtilis BGA (at pH 6.0, 7.2 and 8.0) and Micrococcus luteus ATCC 9341 (at $\mathrm{pH}$ 8.0). For the detection of the presence of sulphonamide residues, the FPT prescribes the Bacillus subtilis BGA at $\mathrm{pH}$ 7.2. The STAR consists of plates with Bacillus subtilis BGA (at pH 7.2), Kocuria varians ATCC 9341 (at pH 8.0), Bacillus cereus ATCC 11778 (at pH 6.0), Escherichia coli ATCC 11303 (at pH 8.0) and Bacillus stearothermophilus var. calidolactis ATCC 10149 (at pH 7.4). For the detection of the presence of sulphonamide residues, the STAR prescribes Bacillus stearothermophilus var. calidolactis ATCC 10149. In order to enhance the sensitivity of the above test organisms to sulphonamides, trimethoprim (TMP) is incorporated in the agar medium at a concentration of $0.05 \mu \mathrm{g} \cdot \mathrm{ml}^{-1}$ and $0.005 \mu \mathrm{g} \cdot \mathrm{ml}^{-1}$, respectively. 
The Premi ${ }^{\circledR}$ Test is an agar diffusion test in ampoules in which the presence of an antibacterial substance in concentration exceeding the LOD is indicated by the absence of colour change from purple to yellow of the indicator (bromocresol purple) in the ampoule. The test organism Bacillus stearothermophilus var. calidolactis is very sensitive to many antibiotics and sulpha compounds.

An ideal screening method would detect all licensed antimicrobials at or below their MRLs. Both techniques are capable of detecting a range of analytes at or below the MRL concentration. Stead et al. (2004) evaluated an alternative solvent extraction technique for enhancement of the capability of the Premi ${ }^{\circledR}$ Test to detect a wider range of drugs at or bellow $1 / 2 \mathrm{MRL}$ in a variety of matrices. They found that the use of the solvent extraction procedure enables effective concentration of the extract to provide increased sensitivity to reach $1 / 2 \mathrm{MRL}$ limits that otherwise would not be achievable.

In practice, the samples showing a positive response are subjected to further investigations based on chromatographic methods with specific detectors. Because the final confirmation step can be preceded by preliminary identification and confirmation of sulphonamides by PABA, the post-screening detection of sulphonamides already in the first stage of the residue screening represents an important step of distinguishing the sulphonamides from other classes of veterinary drugs. In the presence of PABA, sulphonamides became weak and lose their antibacterial activity due to antagonistic competition for the synthesis of hydro-folic acid (Gudding 1974; Gudding 1976; Ferrini et al. 1997; Stead et al. 2004; Kožárová et al. 2005; Janošová et al. 2007a; Janošová et al. 2008).

In food analysis, according to the Commission Decision 2002/657/EC, only chromatographic methods can be used for confirmation (EC 2002). The principal approach of the HPLC analysis involves extraction, sample clean-up and HPLC analysis steps. The choice of method used in the laboratory is often dictated by the availability of suitable expertise, facilities, and equipment. However, all analytical methods used in the testing of official samples taken pursuant to Directive 96/23/EC must fulfil criteria set by the Commission Decision 2002/657/EC (EC 2002).

SMZ has been observed to be effective against coccidiosis in rabbits when it is administered orally via drinking water for 3 consecutive days at the dose of 2 g. $1^{-1}$. To avoid its residues in the edible tissues, a 15-day withdrawal period must be observed before the rabbits are slaughtered for human consumption (Sovík et al. 2005). Because SMZ remains to be the sulphonamide group most widely used in veterinary medicine, the objective of this paper was to determine which of the three aforementioned MIT used in practice today - FPT, 
STAR and Premi ${ }^{\circledR}$ Test - is most sensitive and suitable for the detection of SMZ residues in the edible tissues of rabbits at the level of concern. To detect the SMZ residues at or below the MRL established, we applied an improved screening technique based on multi-residue solvent extraction. PABA at the concentration of $10 \mu \mathrm{g} \cdot \mathrm{ml}^{-1}$ was used to confirm the presence of SMZ residues already during the first stage of residue screening. Finally, the level of SMZ residues in the edible tissues of rabbits was determined by validated HPLC analysis.

All four methods mentioned above have been officially approved for screening foodproducing animals and their products for residues of veterinary drugs in Slovakia $(\mathrm{CH}$ 6.2. 2004; CH 12.16. 2004; CH 12.18. 2006; CH 12.19. 2006).

\section{Materials and methods}

\section{Preparation of standard solutions}

The stock solution $\left(1000 \mu \mathrm{g} \cdot \mathrm{ml}^{-1}\right)$ of the SMZ standard was prepared by dissolving $10 \mathrm{mg}$ of SMZ (Sulfamethazine sodium salt, Sigma S 5637) powder in $2.4 \mathrm{ml}$ ammonia (Lachema, Czech Republic), and diluting it to $10 \mathrm{ml}$ with sterile deionised water. The working solutions of SMZ were prepared by serial dilutions with sterile deionised water to the concentrations of $0.05,0.1,0.2,0.3,0.4,0.5$, and $1 \mu \mathrm{g} \cdot \mathrm{ml}^{-1}$. Control solutions of SMZ $\left(20 \mu \mathrm{g} \cdot \mathrm{ml}^{-1}\right.$ for the FPT and $2 \mu \mathrm{g} \cdot \mathrm{ml}^{-1}$ for the STAR) were used to verify that the operating conditions were systematically respected. The TMP stock solution for the STAR was prepared by dissolving $10 \mathrm{mg}$ of TMP standard (Trimethoprim, Fluka 92131) in $1 \mathrm{ml} \mathrm{5 \%}$ acetic acid (Merck, Germany) and diluting with sterile distilled water to the concentration of $0.5 \mu \mathrm{g} \cdot \mathrm{ml}^{-1}$. The TMP stock solution for the FPT was prepared by dissolving $10 \mathrm{mg}$ of TMP standard in $10 \mathrm{ml}$ ethanol (Frukona, Slovakia) and diluting it with sterile distilled water to the concentration of $5 \mu \mathrm{g} \cdot \mathrm{ml}^{-1}$. The stock solution of PABA $\left(1000 \mu \mathrm{g} \cdot \mathrm{ml}^{-1}\right)$ was prepared by dissolving $10 \mathrm{mg}$ PABA (p-aminobenzoicacid, Sigma A 9878) powder in $10 \mathrm{ml}$ distilled water. All stock and working solutions of respective standards were stored in a refrigerator at $4^{\circ} \mathrm{C}$.

\section{Origin and pre-preparation of incurred samples}

Sixteen rabbits (meat line HY+) 16-weeks old, weighing between $2.60 \mathrm{~kg}-2.90 \mathrm{~kg}$, were obtained for residue analysis from a farm (Hylapa s.r.o., The Slovak Republic). The rabbits were supplied SMZ (Sulfadimidin PG plv. sol. a.u.v., Pharmagal, The Slovak Republic) in drinking water for 3 consecutive days at a dose of 2 g. $\mathrm{l}^{-1}$ of water. After withdrawal of the drug, one rabbit per one day was slaughtered up to day 15 of the WP. The respective samples 


\section{Media and strains}

FPT: Test Agar pH 7.2 (Merck, dehydrated medium 15787, Germany), Bacillus subtilis BGA (Merck 10649, Germany); STAR: Test agar DST pH 7.4 (Oxoid, dehydrated medium CM 261, England), Bacillus stearothermophilus var. calidolactis ATCC 10149 (Merck 1.11499, Germany). Both media were prepared according to the manufacture's instruction.

Premi ${ }^{\circledR}$ Test: Premi ${ }^{\circledR}$ Test kits, Bacillus stearothermophilus var. calidolactis (DSM, The Netherlands), ready to use.

\section{Preparation of test plates}

FPT: Test Agar pH 7.2 was seeded with the test strain Bacillus subtilis BGA to obtain the final concentration of $5 \times 10^{4}$ spores. $\mathrm{ml}^{-1}$ in the agar medium. To obtain the final concentration of TMP in agar medium $\left(0.05 \mu \mathrm{g} \cdot \mathrm{ml}^{-1}\right), 1 \mathrm{ml}$ of TMP solution $\left(5 \mu \mathrm{g} \cdot \mathrm{ml}^{-1}\right)$ was added to $100 \mathrm{ml}$ of agar medium. STAR: Test agar DST pH 7.4 was seeded with the test strain Bacillus stearothermophilus var. calidolactis ATCC 10149 to give a final concentration of $5 \times 10^{6}$ spores. $\mathrm{ml}^{-1}$ in the agar medium. To obtain a final concentration of TMP in agar medium $\left(0.005 \mu \mathrm{g} . \mathrm{ml}^{-1}\right), 1 \mathrm{ml}$ of TMP solution $\left(0.5 \mu \mathrm{g} . \mathrm{ml}^{-1}\right)$ was added to $100 \mathrm{ml}$ of agar medium. Finally, $5 \mathrm{ml}$ of the seeded media were transferred into Petri dishes $90 \mathrm{~mm}$ in diameter.

\section{Determination of LODs}

FPT, STAR: Filter paper discs having a diameter of 12,7 mm (Schleicher \& Schull No. 2668, Germany) moistened with $100 \mu \mathrm{l}$ of respective working solutions of SMZ standard were placed in parallel on the surface of the agar medium in the Petri plates. The plates were 
incubated as follows: the plates seeded with Bacillus subtilis BGA (FPT) at $30^{\circ} \mathrm{C}$ for $18-24 \mathrm{~h}$, and the plates seeded with Bacillus stearothermophilus var. calidolactis ATCC 10149 (STAR) at $55^{\circ} \mathrm{C}$ for $12-15 \mathrm{~h}$.

Premi ${ }^{\circledR}$ Test: $100 \mu$ l of respective working solutions of SMZ standard was pipetted onto the agar in the ampoule. Ampoules were incubated in the DSM heating block incubator for approximately $3 \mathrm{~h}$ at $64 \pm 0.5^{\circ} \mathrm{C}$. Each working solution of SMZ standard was tested four-fold.

\section{Detection of SMZ residues in incurred rabbit samples}

FPT, STAR: A cylindrical core $8 \mathrm{~mm}$ in diameter and $2 \mathrm{~cm}$ long was removed from each frozen sample using a cork borer. To avoid a doubtful result, each cylindrical core was heat pre-treated in a water bath at $71^{\circ} \mathrm{C}$ for $20 \mathrm{~min} .2 \mathrm{~mm}$ slices were cut with a lancet from both end of each core, and were discarded. Eight $2 \mathrm{~mm}$ slices were then cut from the remaining rabbit tissue. The slices and the filter paper discs moistened with $100 \mu$ l of extract were placed in parallel onto the surface of agar medium in Petri dishes. The plates were incubated as follows: the plates seeded with Bacillus subtilis BGA (FPT) at $30^{\circ} \mathrm{C}$ for $18-24 \mathrm{~h}$, and the plates seeded with Bacillus stearothermophilus var. calidolactis ATCC 10149 (STAR) at $55^{\circ} \mathrm{C}$ for $12-15 \mathrm{~h}$.

Premi ${ }^{\circledR}$ Test: Juice from rabbit tissues obtained by the heat pre-treatment of the samples in a volume of $100 \mu \mathrm{l}$ was pipetted onto the agar in the ampoule and allowed to stand at room temperature for $20 \mathrm{~min}$ for pre-diffusion. After pre-diffusion, the juice was flushed away by washing the test twice with demineralised water. The ampoules were incubated in the DSM heating block incubator for approximately $3 \mathrm{~h}$ at $64 \pm 0.5^{\circ} \mathrm{C}$.

\section{Presumptive identification of $S M Z$ residues by $P A B A$}

FPT, STAR: The plates used for the confirmatory purposes were prepared by adding $1 \mathrm{ml}$ of stock solution of PABA to $100 \mathrm{ml}$ of respective agar medium to obtain the confirmatory PABA concentrations $10 \mu \mathrm{g} \cdot \mathrm{ml}^{-1}$ in the agar medium.

Premi ${ }^{\circledR}$ Test: $100 \mu \mathrm{l}$ of stock solution of PABA from the concentration of $100 \mu \mathrm{g} \cdot \mathrm{ml}^{-1}$ was placed onto the agar in the respective ampoules and allowed to stand at room temperature for $20 \mathrm{~min}$ for pre-diffusion. After pre-diffusion, the PABA was discharged from the ampoules and both the working solutions of SMZ standard and examined tissue juice were further tested using the Premi ${ }^{\circledR}$ Test procedure mentioned above. 


\section{Confirmation of the SMZ residues by HPLC}

\section{Solvents and reagents}

All solvents and reagents were analytical or HPLC grade. Acetonitrile, methanol, n-hexane, and acetic acid were obtained from Merck (Darmstadt, Germany), ethyl acetate, anhydrous sodium sulphate, and sodium acetate from Lachema (Brno, Czech Republic), and deionized and redistilled water was prepared on Milli-Q Plus (Millipore, France).

\section{Sample extraction and sample clean-up}

$50 \mathrm{~g}$ homogenized tissue sample (muscle, liver) was extracted with $50 \mathrm{ml}$ of ethyl acetate on a mechanical shaker for $15 \mathrm{~min}$. The extract was filtered through a filtrate paper with $20 \mathrm{~g}$ anhydrous sodium sulphate. The extraction was repeated once more with $50 \mathrm{ml}$ ethyl acetate for $10 \mathrm{~min}$. Both filtrates were collected in a $100 \mathrm{ml}$ round-bottom flask and evaporated to dryness in a rotary vacuum evaporator (Laborota 4000, Heidolph, Merck, Germany) at $40^{\circ} \mathrm{C}$. The residue was re-dissolved in $1 \mathrm{ml}$ methanol and $1 \mathrm{ml}$ of mobile phase, and transferred to a centrifuge tube. The flask was washed twice with $2 \mathrm{mln}$-hexane, and $4 \mathrm{ml}$-hexane was added to the centrifuge tube. The mixture was centrifuged twice at $3500 \mathrm{rpm}$ for $10 \mathrm{~min}$ (Jouan BR 41, France). The lower layer was filtered through a disposable syringe filter unit and transferred to the vial. $25 \mu \mathrm{l}$ volume of the solution was injected into the HPLC system. 


\section{HPLC analysis}

Samples were analysed by a TSP liquid chromatograph (Thermo Separation Products, USA) equipped with a variable UV-VIS detector UV 3000 HR (Hewlett-Packard, USA). The separation was performed on a LiChroCART RP-18e column (125-4, $5 \mu \mathrm{m})$ (Merck, Germany) using an acetonitrile-acetate buffer $(\mathrm{pH} 4,6)(25: 75$, v/v) as a mobile phase at a flow-rate of $0,8 \mathrm{ml} \cdot \mathrm{min}^{-1}$ at the temperature of $40^{\circ} \mathrm{C}$. The detection was conducted at $275 \mathrm{~nm}$.

\section{Results}

The initial experiment was undertaken to detect the LOD of the screening methods for SMZ by determining the MIC of the SMZ standard for the respective test strains of screening methods. Because the MIC is defined as the lowest concentration of the respective antibiotic standard which completely inhibits the growth of the sensitive test organism, the diameters of the inhibition zones (FPT, STAR) and the colour change which represented the positive or negative results (Premi ${ }^{\circledR}$ Test) were evaluated. In an attempt to confirm the presence of SMZ residues already during the first stage of residue screening, PABA at the concentration of 10 $\mu \mathrm{g} . \mathrm{ml}^{-1}$ was used. This PABA concentration was taken into consideration according to the results obtained in our preliminary studies (Kožárová et al. 2005; Janošová et al. 2007a). All the results are summarized in Table I. Our results showed that the MIC of SMZ was 0.4 $\mu \mathrm{g} \cdot \mathrm{ml}^{-1}$ for FPT, $0.2 \mu \mathrm{g} \cdot \mathrm{ml}^{-1}$ for STAR, and $0.05 \mu \mathrm{g} \cdot \mathrm{ml}^{-1}$ for Premi ${ }^{\circledR}$ Test /A/. By adding PABA to the agar medium (FPT, STAR) or onto the top of the agar medium (Premi ${ }^{\circledR}$ Test), the absence of the inhibition zones or yellow colour was observed /B/.

The results of the screening for the presence of SMZ residues in the edible tissues of rabbits after its oral administration up to day 15 of the withdrawal period are presented in Tables II, III, and IV. Tables II and III show the mean diameters of the inhibition zones $(\mathrm{mm} \pm \mathrm{SD} /$ standard deviation/) produced by SMZ residues around the examined rabbit tissues and discs moistened with the extract from the rabbit muscle. Table IV shows the sensitivity of the test towards SMZ residues presented in the juice from rabbit tissue. By adding PABA to the agar medium (FPT, STAR) or onto the top of the agar medium (Premi ${ }^{\circledR}$ Test), no positive results were detected. PABA at the concentration of $10 \mu \mathrm{g} \cdot \mathrm{ml}^{-1}$ completely reversed the inhibitory activity of SMZ and identified reliably the presence of SMZ in the examined samples. Because all results with plates B or ampoules B were identical (0 /FPT, STAR/, /Premi ${ }^{\circledR}$ Test/), Tables II, III, and IV contain the results observed at the screening of SMZ residues in edible tissues of rabbits only with plates $\mathrm{A}$. 
No detection sensitivity presented by the absence of the inhibition zones around the examined rabbit tissues was observed when using the FPT (Table II. /A/). When using the solvent extraction, the FPT detected the presence of SMZ residues in examined rabbit muscle tissue until day 8 of the WP. Because the FPT designated the sample positive at the inhibition zone of $2 \mathrm{~mm}$ and more, the muscle was positive until day 3 of the WP, and the mean diameter of the inhibition zone was $2.83 \pm 0.13 \mathrm{~mm}$. According to the results obtained by screening of the SMZ standard, the residual concentration of SMZ in the positive muscle tissue was $0.4-0.5 \mu \mathrm{g} \cdot \mathrm{g}^{-1}$.

The STAR detected SMZ residues in the examined rabbit tissues (lungs, liver and kidneys) until day 8 of the WP. No SMZ residues were detected in the muscle and heart (Table III. /A/). Because the STAR rated the sample positive if the inhibition zone was $4 \mathrm{~mm}$ and greater, the liver was positive until day 4 of the WP (mean inhibition zone $4.21 \pm 0.08$ $\mathrm{mm}$ ), the lungs were positive until day 3 of the WP (mean inhibition zone $4.01 \pm 0.48 \mathrm{~mm}$ ), and the kidneys were positive until day 5 of the WP (mean inhibition zone $4.35 \pm 0.25 \mathrm{~mm}$ ). According to the results obtained by screening of the SMZ standard, the residual concentration of SMZ in the presented positive rabbit tissue was in the range of $0.4-0.5 \mu \mathrm{g} . \mathrm{g}^{-}$ ${ }^{1}$. After isolation of SMZ residues from the muscle by solvent extraction, the SMZ residues were detected in the muscle extract until day 10 of the WP and the muscle was positive until day 6 of the WP (mean inhibition zone 4.32 \pm 0.19 ). According to the results obtained by screening of the SMZ standard, the residual concentration of SMZ in the presented positive rabbit muscle tissue was $0.4-0.5 \mu \mathrm{g} \cdot \mathrm{g}^{-1}$.

The Premi ${ }^{\circledR}$ Test detected SMZ residues in all examined matrices. By using the fluid expression procedure, the muscle and heart were positive until day 9 of the WP, and the liver, lungs and kidneys until day 10 of the WP (Table IV /A/). The positive results manifested by the maintenance of the violet colour of the agar medium imply the presence of SMZ residues at or above the LOD of the method. The negative results manifested by decolouration of the agar medium imply the absence of SMZ or presence of its residues below the LOD of the method. According to the results obtained by screening of the SMZ standard we can assume that the residual concentration of SMZ in the presented positive rabbit tissues was $0.05 \mu \mathrm{g} \cdot \mathrm{ml}^{-}$ 1 .

No positive results implied by the presence of inhibition zones or by maintenance of violet colour of the agar medium were observed in all examined rabbit tissues obtained from SMZ-free control group. 


\section{HPLC analysis}

The presence of SMZ residues in the rabbit tissues (muscle, liver) throughout the 15 days of the WP were consequently confirmed and quantified by HPLC. The LOD of the method for SMZ was $0.004 \mathrm{mg} . \mathrm{kg}^{-1}$ and the respective limit of quantification (LOQ) for SMZ was 0.010 mg. $\mathrm{kg}^{-1}$. Recoveries of SMZ from spiked control sample at the concentration from $0,3 \mathrm{mg} \cdot \mathrm{kg}^{-1}$ to $3 \mathrm{mg} \cdot \mathrm{kg}^{-1}$ ranged between $83 \%$ and $88 \%$. SMZ residues were detected with UV-VIS detector at $275 \mathrm{~nm}$ at the retention time between 6.958 and $7.731 \mathrm{~min}$. The mean residue concentrations of SMZ (mg. $\left.\mathrm{kg}^{-1}\right)$ in the examined samples are shown in Table V.

Table $\mathrm{V}$ shows that SMZ residues were detected in both examined matrices and the decrease in SMZ level was gradual and very slow. The highest residue concentrations were found on the first day of the WP. On this day, the mean residue concentration of SMZ in the liver was $0.56 \mathrm{mg} \cdot \mathrm{kg}^{-1}$, and in the muscle it was $0.42 \mathrm{mg} \cdot \mathrm{kg}^{-1} . \mathrm{SMZ}$ residues in the liver of rabbits were detectable up to day 12 of the WP and the mean SMZ residue concentration was $0.09 \mathrm{mg} \cdot \mathrm{kg}^{-1}$. On day 13 of the WP, SMZ residues were below the LOD of the method. SMZ residues in the rabbit muscles were detectable up to day 10 of the WP and the mean SMZ residue concentration was $0.02 \mathrm{mg} \cdot \mathrm{kg}^{-1}$. On the day 11 of the WP, SMZ residues were below the LOD of the method. No residues of SMZ were found in the muscles and liver obtained from the SMZ-free control group.

\section{Discussion}

The presence of contaminants and veterinary drug residues in products of animal origin is a matter of concern for public health (Danko et al. 2005; Koréneková et al. 2007; Lukáč and Massányi 2007). The strategy of official residue control is based on two sequential steps: screening and confirmation. According to the Commission Decision 2002/657/EC a screening method means method that is used to detect the presence of a substance or class of substances at the level of interest. Screening methods have the capability for a high sample throughput and are used to sift large number of samples for potential non-compliant results. They are specifically designed to avoid false compliant results. Confirmatory method means method that provides full or complementary information enabling the substance to be unequivocally identified and, if necessary, quantified at the level of interest. The level of interest means the concentration of substance or analyte in a sample that is significant for determination of its compliance with legislation (EC 2002).

Live animals and animal products are often screened for antibiotic and sulphonamide residues in the first stage of residue screening by using the microbial inhibition tests. There is 
a whole range of such tests with various test organisms used worldwide. The LOD of the MIT for a given antibacterial depends primarily on the innate sensitivity of the test organism. In sulphonamide residue screening, four test organisms, namely Bacillus subtilis BGA, Bacillus megaterium ATCC 9885, Bacillus stearothermophilus var. calidolactis, and Bacillus pumilus have been most widely used and investigated. The published data show that their sensitivity is not equal for all compounds of the sulphonamide group. Their sensitivity to sulphonamides were often affected by differences in test media, depth of agar layers, $\mathrm{pH}$ value of the agar medium, addition of TMP or dextrose to the agar medium, temperature, preparation and application of the standard solution, animal tissues, etc. (Bogaerts and Wolf 1980; Hrdlička 1990; Heitzman 1994; Koenen-Dierick and De Beer 1998; Okerman and Van Hoof 1998; Okerman et al. 1998; Korsrud et al. 1998; Hussein 2004; Gaudin et al. 2004; Dey et al. 2005; Kožárová and Labanská 2005; Janošová et al. 2007b; Pikkemaat et al. 2008).

PABA specifically inhibits the bacteriostatic activity of sulphonamides. Many authors investigated PABA at its various concentrations (from $0.1 \mu \mathrm{g} \cdot \mathrm{ml}^{-1}$ to $100 \mu \mathrm{g} \cdot \mathrm{ml}^{-1}$ ) for identification of sulphonamide residues at the first stage of their residue screening (Lin et al. 1995; Ferrini et al. 1997; Braham et al. 2001; Stead et al. 2004; Kožárová et al. 2005, Janošová et al. 2007a, Janošová et al. 2008). All authors found that in the absence of PABA, sulphonamides produced inhibition zones on the test plates, whereas in its presence, no inhibition zones or reduction of their diameters were observed. The confirmatory PABA concentration was often conditioned by respective TMP concentration in the agar medium.

Chemical denaturation of tissues assists with release of drug residues. Stead et al. (2004) improved screening technique for rapid detection of antimicrobial residues in animal food products using of a solvent extraction procedure. The use of the solvent extraction technique coupled to the Premi ${ }^{\circledR}$ Test provides an enhanced test capable of detecting a wider range of drugs at or below maximum residue limit concentrations. A solvent ratio of 70:30 v/v acetonitrile/acetone was found experimentally to be optimum for extracting the widest range of analytes including sulphonamides.

The samples showing positive responses are subjected to further investigations by quantitative physico-chemical analysis. Chromatographic methods are being developed to confirm the findings of the screening methods. To determine sulphonamide residues in different matrices, several chromatographic methods based on HPLC with ultraviolet, fluorescence or mass spectrometry detection have been used in practise.

Bearing in mind these consideration, the aim of our study was to evaluate three MIT used in practise today, the FPT containing Bacillus subtilis BGA, the STAR containing Bacillus 
stearothermophilus var. calidolactis ATCC 10149, and the Premi ${ }^{\circledR}$ Test containing Bacillus stearothermophilus var. calidolactis, for determining SMZ residues in the edible tissues of rabbits after its oral administration up to day 15 of the withdrawal period at the level of concern. To obtain reliable results already in the first stage of residue screening and to identify the presence of SMZ residues in the examined rabbit samples, both the screening procedure based on solvent extraction step and the post-screening identification of SMZ by PABA were used. The confirmatory analysis was undertaken by validated HPLC method.

The LODs of all tested MIT for SMZ were determined by detecting the MIC of SMZ standard which inhibited the growth and multiplication of the test organism with the respective method. The test organism Bacillus stearothermophilus var. calidolactis showed higher sensitivity to SMZ than the test organism Bacillus subtilis BGA. According to our results, the LOD of MIT for SMZ were as follows: FPT $0.4 \mu \mathrm{g} \cdot \mathrm{ml}^{-1}$, STAR $0.2 \mu \mathrm{g} \cdot \mathrm{ml}^{-1}$, and Premi ${ }^{\circledR}$ Test $0.05 \mu \mathrm{g} \cdot \mathrm{ml}^{-1}$. The Premi ${ }^{\circledR}$ Test detected SMZ residues (positive results) in the muscles and heart tissues until day 9 of the WP, and in the liver, lungs and kidneys until day 10 of the WP. The STAR detected SMZ residues in the edible organs of rabbits until day 8 of the WP. The kidneys were positive until day 5 of the WP, the liver until day 4 of the WP, and the lungs until day 3 of the WP. No SMZ residues were detected in the muscle and heart. The FPT detected no SMZ residues in any examined matrices.

The use of the solvent extraction significantly improved the existing screening methodology of plate agar diffusion methods and confirmed the data presented by the author mentioned above. Mixture of acetonitrile/acetone at a solvent ratio of 70:30 v/v, enabled extraction of SMZ residue from "negative" muscle tissues and enhanced the capability of the STAR and the FPT for detecting SMZ residues at the level of interest. By using the STAR, SMZ residues were detected in the muscle extract until day 10 of the WP. The muscles were positive until day 6 of the WP. By using the FPT, SMZ residues were detected in the muscle extract until day 8 of the WP and the muscles were positive until day 3 of the WP.

PABA, at the concentration of $10 \mu \mathrm{g} \cdot \mathrm{ml}^{-1}$ completely inhibited the antibacterial effect of SMZ in all examined matrices. The absence of inhibition zones around the examined matrices on PABA containing agar and visible decolourization of the agar medium from purple to yellow after adding PABA to the ampoule indicated the presence of SMZ residues in the samples. These results confirmed that PABA is an efficient and reliable agent for presumptive identification of SMZ residues in screen-positive samples.

The choice of method for confirmatory residue analysis is often dictated by the availability of suitable facilities and equipment. The HPLC method used in our study was 


\section{Conclusions}

The residue-monitoring process is critical to the protection of the consumer's health. It must be effective and match the patterns of use for all classes of drugs applied in animal-production system, including sulphonamides. MIT are highly valuable in the first stage of residue screening. The purpose of these screening methods is to give a quick result whether the residue is either not present in the sample or is at or bellow the level of interest. With regard to their excellent practicality and throughput, they allow us to classify a large number of samples as being either "negative" or "potentially positive". All potentially positive samples are then subjected to a confirmatory test.

Because SMZ is still widely used for the treatment of coccidiosis in all food-producing animals, SMZ residues remain an important consideration for consumers. Thus the objective of the present work was to detect which of the three aforementioned MIT, used in practise today, the FPT, the STAR and the Premi ${ }^{\circledR}$ Test, is most suitable for relevant detection of SMZ residue in the edible tissues of rabbits without any risk for consumers. Our results showed that the commercially produced Premi ${ }^{\circledR}$ Test is by far the most suitable MIT for the detection of SMZ residues bellow the level of the MRL $0.1 \mathrm{mg} \cdot \mathrm{kg}^{-1}$. The STAR detected SMZ residues closely above the MRL level, and the FPT above the MRL level. This indicates that the MIT containing Bacillus stearothermophilus var. calidolactis the test organism are more sensitive to SMZ than those with Bacillus subtilis BGA. When the edible tissues of rabbits were screened by classical methodologies of the STAR and the FPT, no SMZ residues were detected in the rabbit muscles. The alternative screening technique based on solvent extraction 
permitted apparent enhancement of the test detection capability and improved positive results of both less sensitive MIT. Because the MIT are sensitive to a wide range of antimicrobial compounds, the use of PABA in post-screening investigation of the screen-positive samples allowed us to identify the presence of SMZ residues in the examined samples and choose the method suitable for confirmatory analysis. HPLC analysis of muscle and liver samples of rabbits confirmed the presence of SMZ residues in both examined matrices.

The results obtained allowed us to conclude that the Premi ${ }^{\circledR}$ Test and the STAR with the test organism Bacillus stearothermophilus var. calidolactis ATCC 10149 in combination with the alternative screening technique based on the solvent extraction procedure, can be used as the most suitable screening tests for detection of SMZ residues in the edible tissues of rabbits at the level corresponding to MRL of $0.1 \mathrm{mg} \cdot \mathrm{kg}^{-1}$. The utilisation of PABA for the presumptive identification of SMZ residues in the screen-positive samples constitutes an impressive challenge to employ efficient and cost-effective means of controlling SMZ residues in foods.

\section{Acknowledgements}

This study was supported by VEGA grant No 1/3491/06.

\section{References}

Bogaerts R, Wolf F. 1980. A standardised method for the detection of residues of antibacterial substances in fresh meat. Fleischwirtschaft 60:672-673.

Braham R, Black WD, Claxton J, Yee J. 2001. A rapid assay for detecting sulfonamides in tissues of slaughtered animals. Journal of Food Protection 64:1565-1573.

EC. 1990. Council Regulation (EEC) No. 2377/90 of 26 June 1990 laying down a Community procedure for the establishment of maximum residue limits of veterinary medicinal products in foodstuffs of animal origin. Official Journal L 224:1-8.

EC. 1996. Council Directive 96/23/EC of 29 April 1990 establish on measures to monitor certain substances and residues thereof in live animals and animal products. Official Journal L 125:10-32.

EC. 2002. Commission Decision 2002/657/EC of 12 August 2002 implementing Council Directive 96/23/EC concerning the performance of analytical methods and the interpretation of results. Official Journal L 221:8-28. 
Danko J, Lešník F, Jenča A. 2005. Xenobiotics and their relation to health. Košice: University of Veterinary Medicine, $107 \mathrm{pp}$.

Dey BP, Reamer RP, Thaker NH, Thaler AM. 2005. Calf antibiotic and sulfonamide test (CAST) for screening antibiotic and sulfonamide residues in calf carcasses. Journal of AOAC International 88:440-446.

Ferrini AM, Mannoni V, Aureli P. 1997. The Combinated Plates Microbial Assay (CPMA) technique for the detection and presumptive identification of $\beta$-lactam, sulfonamide, streptomycin and tetracycline residues in meat. Arch. Lebensmittelhygiene 48:121-144.

Gaudin V, Maris P, Fuselier R, Ribouchon JL, Cadieu N, Rault A. 2004. Validation of a microbiological method: the STAR protocol, a five-plate test, for the screening of antibiotic residues in milk. Food Additives and Contaminants 21: 422-433.

Gudding R. 1974. The suitability of some media and peptones for sulfonamide testing. Acta Veterinaria Scan. 15:366-380.

Gudding R. 1976. An improved bacteriological method for the detection of sulfonamide residues in food. Acta Veterinaria Scan.17:458-464.

Heitzman RJ, editor. 1998. Veterinary Drug Residues - Residues in Food producing Animals and their Products: Reference Materials and Methods. $2^{\text {nd }}$ edition. Oxford: Blackwell Scientific Publications.

Hrdlička J. 1990. The residues of inhibitory substances in the times of slaughter animals comparison of microbiological methods of agar diffusion. Veter. Med. 35:411-418.

Hussein K. 2004. Experimental design for the microbiological Four-plate test for the detection of sulphadimidine residues at the level of the concern. Bull Vet Inst Pulawy 48.403-407.

CH 6.2. 2004. Determination of sulphonamides by HPCL method. In: List of official methods for laboratory diagnostics of food and feed, Bulletin of the Ministry of Agriculture of the Slovak Republic 36:97-99.

CH 12.16. 2004. Detection of the residues of inhibitory substances. The Four Plate Test (Bogaerts and Wolf, 1980). In: List of official methods for laboratory diagnostics of food and feed, Bulletin of the Ministry of Agriculture of the Slovak Republic 36:277-284.

CH 12.18. 2006. Determination of residues of inhibitory substances in meat by the Premi ${ }^{\circledR}$ Test. In: List of official methods for laboratory diagnostics of food and feed, Bulletin of the Ministry of Agriculture of the Slovak Republic 38:64-67.

$\mathrm{CH}$ 12.19. 2006. Screening test for determination of antibiotic residues using bacterial strains (STAR). In: List of official methods for laboratory diagnostics of food and feed, Bulletin of the Ministry of Agriculture of the Slovak Republic 38:68-81. 
Janošová J, Kožárová I, Máté D, Kovaliková M. 2007a. Detection of sulphonamide residues by Screening Test for Antibiotic Residues (STAR) and utilisation of para-aminobenzoic acid (PABA) for their presumptive identification. Folia Veterinaria 51:52-56.

Janošová J, Kožárová I, Máté D, Kovaliková M. 2007b. A comparison of the sensitivity of antibiotic residue screening methods - the Four Plate Test (FPT), the Screening Test for Antibiotic Residues (STAR), and the Premi ${ }^{\circledR}$ Test to sulphonamide standards. Meso 1:3743.

Janošová J, Kožárová I, Máté D, Okerman L. 2008. A comparison of the sensitivity of antibiotic residue screening methods to sulphonamide standards and their presumptive identification by para-aminobenzoic acid. Medycyna Weterynaryjna 64:663-667.

Koenen-Dierick K, De Beer JO. 1998. Optimization of an antibiotic residue screening test, based on inhibition of Bacillus subtilis BGA, with experimental design. Food Additives and Contaminants 15:528-534.

Korsrud, GO, Boison JO, Nouws JFM, MacNeil JD. 1998. Bacterial Inhibition Tests Used to Screen for Antimicrobial Veterinary Drug Residues in Slaughter Animals. Journal of AOAC International 81: 21-24.

Koréneková B, Skalická M, Nad’ P, Korének, M. 2007: Occurence of selected trace elements in cattle meat. Meso 9:328-331.

Kožárová I, Janošová J, Máté D, Pipová M, Jevinová P. 2005. A utilization of paraaminobenzoic acid (PABA) for the presumtive identification of sulphadimidine at its residue screening by using the microbiological Four-plate test. Bull. Vet. Inst. Pulawy 49:59-64.

Kožárová I., Labanská D. 2005. Comparison study of estimation of detection sensitiveness of microbial inhibitory tests used for screening of sulphonamides in practise. In: Proceeding Book (Abstracts) of 5-th International Scientific Conference Risk factors of food chain, Nitra: Slovak University of Agriculture, October 6 2005, 24.

Lin CHL, Hong CHCH, Kondo F. 1995. Simultaneous determination of residual sulphonamides in the presence and absence of $p$-aminobenzoic acid by high-performance liquid chromatography. Microbios 83:175-183.

Lukáč N., Massányi P. 2007. Effects of trace elements on the immune system. Epidemiologie, Mikrobiologie, Imunologie 56:3-9.

Okerman L., Van Hoof J. 1998: Evaluation of the European Four-Plate Test as a tool for screening antibiotic residues in meat samples from retail outlets. Journal of AOAC International 81:51-56. 
Okerman L, De Wasch K, Van Hoof J. 1998. Detection of antibiotics in muscle tissue with microbiological inhibition tests: effects of the matrix. Analyst 123: 2361-2365.

Pikkemaat MG, Oostra-van Dijk S, Schouten J, Rappaline M, Van Egmond HJ. 2008. A new microbiological screening method for the detection of antimicrobial residues in slaughter animals: the Nouws antibiotic test (NAT-screening). Food Control 19: 781-789.

Sovík L, Hederová J, Bíreš J, Gajdoš M. et al. 2005. Vademecum of veterinary preparations and disinfestation aids. Bratislava: Pro-Trade.

Stead S, Sharman JA, Tarbin JA, Gibson E, Richmond S, Stark J, Geijp E. 2004. Meeting maximum residue limits: an improved screening technique for rapid detection of antimicrobial residues in animal food products. Food Additives and Contaminants 21:216-221. 
Table I. LOD of screening methods for SMZ determined by the MIC of SMZ standard presented as the lowest mean diameter of the inhibition zones $(\mathrm{mm} \pm \mathrm{SD})$ or positive results (A) and presumptive identification of SMZ with PABA at the concentration of $10 \mu \mathrm{g} \cdot \mathrm{ml}^{-1}$ (B).

\begin{tabular}{ccccccccc}
\hline & Plate/ & \multicolumn{7}{c}{ Concentration of SMZ $\left(\mu \mathrm{g} . \mathrm{ml}^{-1}\right)$} \\
\cline { 3 - 9 } MIT & Ampoule & $\mathbf{0 . 0 5}$ & 0.1 & $\mathbf{0 . 2}$ & 0.3 & $\mathbf{0 . 4}$ & 0.5 & 1 \\
\hline FPT & A & 0 & 0 & 0 & 0 & $\mathbf{2 . 6 2} \pm \mathbf{0 . 2 6}$ & $3.09 \pm 0.17$ & $3.67 \pm 0.14$ \\
& $\mathrm{~B}$ & 0 & 0 & 0 & 0 & 0 & 0 & 0 \\
STAR & $\mathrm{A}$ & 0 & 0 & $\mathbf{1 . 0 9} \pm \mathbf{0 . 4 8}$ & $2.17 \pm 0.75$ & $3.17 \pm 1.17$ & $4.00 \pm 0.63$ & $5.00 \pm 0.63$ \\
& $\mathrm{~B}$ & 0 & 0 & 0 & 0 & 0 & 0 & 0 \\
Premi $^{\circledR}$ & $\mathrm{A}$ & + & + & + & + & + & + & + \\
Test & $\mathrm{B}$ & - & - & - & - & - & - & - \\
\hline
\end{tabular}

Bold concentrations represent the LOD of respective MIT for SMZ; + positive results; All data are the mean \pm SD of six observations. 
Table II. The mean diameters of the inhibition zones $(\mathrm{mm} \pm \mathrm{SD})$ observed at the screening of SMZ residues in edible tissues of rabbits after its oral administration up to the day 15 of the withdrawal period using the FPT with Bacillus subtilis BGA at pH 7.2.

\begin{tabular}{c|c|c|c|c|c|c|c} 
Day of WP & Plate & Muscle & Muscle extract & Heart & Liver & Lungs & Kidneys \\
\hline 1. & A & 0 & $8.04 \pm 1.07$ & 0 & 0 & 0 & 0 \\
\hline 2. & A & 0 & $4.79 \pm 0.35$ & 0 & 0 & 0 & 0 \\
\hline 3. & A & 0 & $2.83 \pm 0.13$ & 0 & 0 & 0 & 0 \\
\hline 4. & A & 0 & $1.73 \pm 0.26$ & 0 & 0 & 0 & 0 \\
\hline 5. & A & 0 & $1.72 \pm 0.15$ & 0 & 0 & 0 & 0 \\
\hline 6. & A & 0 & $1.64 \pm 0.12$ & 0 & 0 & 0 & 0 \\
\hline 7. & A & 0 & $1.46 \pm 0.23$ & 0 & 0 & 0 & 0 \\
\hline 8. & A & 0 & $0.75 \pm 0.60$ & 0 & 0 & 0 & 0 \\
\hline 9.-15. & A & 0 & 0 & 0 & 0 & 0 & 0 \\
\hline Control sample & A & 0 & 0 & 0 & 0 & 0 & 0 \\
\hline
\end{tabular}

A - plates without the addition of PABA into the agar medium; Bold numerals represent the positive results; All data are the mean $\pm \mathrm{SD}$ of four observations. 
Table III. The mean diameters of the inhibition zones $(\mathrm{mm} \pm \mathrm{SD})$ observed at the screening of SMZ residues in edible tissues of rabbits after its oral administration up to the day 15 of the withdrawal period using the STAR with Bacillus stearothermophilus ATCC 10149 at pH 7.4.

\begin{tabular}{cccccccc}
\hline Day of WP & Plate & Muscle & Muscle extract & Heart & Liver & Lungs & Kidneys \\
\hline 1. & A & 0 & $\mathbf{9 . 9 1} \pm \mathbf{0 . 5 5}$ & 0 & $\mathbf{8 . 1 2} \pm \mathbf{1 . 7 8}$ & $\mathbf{5 . 8 5} \pm \mathbf{0 . 6 7}$ & $\mathbf{8 . 7 5} \pm \mathbf{0 . 3 9}$ \\
2. & $\mathrm{~A}$ & 0 & $\mathbf{8 . 1 6} \pm \mathbf{1 . 0 4}$ & 0 & $\mathbf{5 . 3 9} \pm \mathbf{0 . 6 7}$ & $\mathbf{4 . 1 7} \pm \mathbf{0 . 6 3}$ & $\mathbf{6 . 5 3} \pm \mathbf{0 . 2 0}$ \\
3. & $\mathrm{~A}$ & 0 & $\mathbf{7 . 9 3} \pm \mathbf{1 . 0 1}$ & 0 & $\mathbf{4 . 4 6} \pm \mathbf{0 . 5 3}$ & $\mathbf{4 . 0 1} \pm \mathbf{0 . 4 8}$ & $\mathbf{5 . 5 9} \pm \mathbf{1 . 3 0}$ \\
4. & $\mathrm{~A}$ & 0 & $\mathbf{6 . 6 5} \pm \mathbf{1 . 3 9}$ & 0 & $\mathbf{4 . 2 1} \pm \mathbf{0 . 0 8}$ & $2.42 \pm 0.49$ & $\mathbf{4 . 4 5} \pm \mathbf{0 . 7 1}$ \\
5. & $\mathrm{~A}$ & 0 & $\mathbf{5 . 0 1} \pm \mathbf{0 . 5 7}$ & 0 & $2.54 \pm 0.66$ & $1 ., 28 \pm 0.25$ & $\mathbf{4 . 3 5} \pm \mathbf{0 . 2 5}$ \\
6. & $\mathrm{~A}$ & 0 & $\mathbf{4 . 3 2} \pm \mathbf{0 . 1 9}$ & 0 & $2.01 \pm 0.51$ & $1.08 \pm 0.23$ & $3.05 \pm 0.26$ \\
7. & $\mathrm{~A}$ & 0 & $2.36 \pm 0.38$ & 0 & $1.66 \pm 0.13$ & $0.71 \pm 0.84$ & $2.53 \pm 0.19$ \\
8. & $\mathrm{~A}$ & 0 & $2.31 \pm 0.28$ & 0 & $1.57 \pm 1.08$ & $0.63 \pm 0.76$ & $1.95 \pm 0.27$ \\
9. & $\mathrm{~A}$ & 0 & $2.26 \pm 0.90$ & 0 & 0 & 0 & 0 \\
10. & $\mathrm{~A}$ & 0 & $1.29 \pm 0.51$ & 0 & 0 & 0 & 0 \\
$11 .-15$. & $\mathrm{A}$ & 0 & 0 & 0 & 0 & 0 & 0 \\
Control sample & $\mathrm{A}$ & 0 & 0 & 0 & 0 & 0 & 0 \\
\hline
\end{tabular}

A - plates without the addition of PABA into the agar medium; Bold numerals represent the positive results; All data are the mean \pm SD of four observations. 
Table IV. Positive and negative results observed at the screening of SMZ residues in edible tissues of rabbits after its oral administration up to the day 15 of the withdrawal period using the Premi ${ }^{\circledR}$ Test.

\begin{tabular}{ccccccc} 
Day of WP & Ampoule & Muscle & Heart & Liver & Lungs & Kidneys \\
\hline 1. & A & + & + & + & + & + \\
\hline 2. & A & + & + & + & + & + \\
\hline 3. & A & + & + & + & + & + \\
\hline 4. & A & + & + & + & + & + \\
\hline 5. & A & + & + & + & + & + \\
\hline 6. & A & + & + & + & + & + \\
\hline 7. & A & + & + & + & + & + \\
\hline 8. & A & + & + & + & + & + \\
\hline 9. & A & + & + & + & + & + \\
\hline 10. & A & - & - & + & + & + \\
\hline $11 .-15$. & A & - & - & - & - & - \\
\hline Control sample & A & - & - & - & - & - \\
\hline
\end{tabular}

A - ampoule without the addition of PABA onto the agar medium; + positive results; negative results; All data are the mean \pm SD of four observations. 
Table V. SMZ-residue concentrations (mg.kg ${ }^{-1} \pm \mathrm{SD}$ ) in the rabbit muscle and liver after its oral administration up to the day 15 of the withdrawal period detected by the HPLC.

\begin{tabular}{ccc}
\hline Day of WP & Muscle & Liver \\
\hline 1. & $0.42 \pm 0.046$ & $0.56 \pm 0.021$ \\
2. & $0.38 \pm 0.011$ & $0.49 \pm 0.032$ \\
3. & $0.33 \pm 0.033$ & $0.41 \pm 0.017$ \\
4. & $0.33 \pm 0.015$ & $0.39 \pm 0.009$ \\
5. & $0.27 \pm 0.007$ & $0.39 \pm 0.011$ \\
6. & $0.25 \pm 0.004$ & $0.31 \pm 0.013$ \\
7. & $0.21 \pm 0.025$ & $0.27 \pm 0.015$ \\
8. & $0.18 \pm 0.016$ & $0.25 \pm 0.008$ \\
9. & $0.15 \pm 0.002$ & $0.21 \pm 0.050$ \\
$\mathbf{1 0 .}$ & $\mathbf{0 . 0 2} \pm \mathbf{0 . 0 0 4}$ & $0.21 \pm 0.070$ \\
11. & ND & $0.19 \pm 0.006$ \\
$\mathbf{1 2 .}$ & ND & $\mathbf{0 . 0 9} \pm \mathbf{0 . 0 0 3}$ \\
$13 .-15$. & ND & ND \\
\hline
\end{tabular}

Bold numerals represent the days of the WP when the lowest residue levels were measured; ND - not detectable. 